\title{
Neuromuscular NMDA Receptors Modulate Developmental Synapse Elimination
}

\author{
-Kirkwood E. Personius, ${ }^{1,2}$ Barbara S. Slusher, ${ }^{4}$ and ${ }^{-S u s a n ~ B . ~ U d i n ~}{ }^{1,3}$ \\ ${ }^{1}$ Program in Neuroscience, ${ }^{2}$ Department of Rehabilitation Science, School of Public Health and Health Professions, and ${ }^{3}$ Department of Physiology and \\ Biophysics, School of Medicine and Biomedical Sciences, University at Buffalo, Buffalo, New York 14214, and ${ }^{4}$ Department of Neurology and Psychiatry, \\ The Johns Hopkins University School of Medicine, Baltimore, Maryland 21205
}

At birth, each mammalian skeletal muscle fiber is innervated by multiple motor neurons, but in a few weeks, all but one of those axons retracts (Redfern, 1970) and differential activity between inputs controls this phenomenon (Personius and Balice-Gordon, 2001; Sanes and Lichtman, 2001; Personius et al., 2007; Favero et al., 2012). Acetylcholine, the primary neuromuscular transmitter, has long been presumed to mediate this activity-dependent process (O'Brien et al., 1978), but glutamatergic transmission also occurs at the neuromuscular junction (Berger et al., 1995; Grozdanovic and Gossrau, 1998; Mays et al., 2009). To test the role of neuromuscular NMDA receptors, we assessed their contribution to muscle calcium fluxes in mice and tested whether they influence removal of excess innervation at the end plate. Developmental synapse pruning was slowed by reduction of NMDA receptor activation or expression and by reduction of glutamate production. Conversely, pruning is accelerated by application of exogenous NMDA. We also found that NMDA induced increased muscle calcium only during the first 2 postnatal weeks. Therefore, neuromuscular NMDA receptors play previously unsuspected roles in neuromuscular activity and synaptic pruning during development.

Key words: competition; glutamate; neuromuscular junction; polyneuronal; synapse elimination

\section{Significance Statement}

In normal adult muscle, each muscle fiber is innervated by a single axon, but at birth, fibers are multiply innervated. Elimination of excess connections requires neural activity; because the neuromuscular junction (NMJ) is a cholinergic synapse, acetylcholine has been assumed to be the critical mediator of activity. However, glutamate receptors are also expressed at the NMJ. We found that axon removal in mice is slowed by pharmacological and molecular manipulations that decrease signaling through neuromuscular NMDA receptors, whereas application of exogenous NMDA at the NMJ accelerates synapse elimination and increases muscle calcium levels during the first 2 postnatal weeks. Therefore, neuromuscular NMDA receptors play previously unsuspected roles in neuromuscular activity and elimination of excess synaptic input during development.

\section{Introduction}

The mammalian neuromuscular junction (NMJ) has long served as a model system for studying the role of activity in pruning excess innervation (Thompson, 1983). Immature muscle end

Received April 7, 2016; revised June 6, 2016; accepted June 27, 2016.

Author contributions: K.E.P., B.S.S., and S.B.U. designed research; K.E.P. and S.B.U. performed research; K.E.P. B.S.S., and S.B.U. contributed unpublished reagents/analytic tools; K.E.P. and S.B.U. analyzed data; K.E.P. and S.B.U. wrote the paper.

This work was supported by the University at Buffalo (Rehabilitation Science Collaborative Grant to K.E.P. and S.B.U.) and the National Institutes of Health (Grant R01 CA161056 to B.S.S.). We thank M. Morales for advice on the sequence of the mouse NMDA receptor; C. Garcia, M. Bancone, and E. Kubiniec for assistance with data analysis; and Joan S. Baizer for cogent comments on the manuscript.

The authors declare no competing financial interests.

Correspondence should be addressed to Kirkwood E Personius, P.T., Ph.D., Dept. of Rehabilitation Science, University at Buffalo, Kimball Tower Rm. 515, 3435 Main St., Buffalo, NY 14214-3079. E-mail: kep7@buffalo.edu.

https://doi.org/10.1523/JNEUROSCl.1181-16.2016

Copyright $\odot 2016$ the authors $\quad 0270-6474 / 16 / 368783-07 \$ 15.00 / 0$ plates are initially innervated by as many as 10 motor neurons, but within a few weeks in mice, all but one synaptic input is lost. This pruning process is controlled by differential activity levels between competing motor neurons, with the more active input gaining synaptic territory and retraction of the less active input (Personius and Balice-Gordon, 2001; Sanes and Lichtman, 2001; Personius et al., 2007; Favero et al., 2012).

It has seemed logical that acetylcholine (Ach), as the well established neuromuscular transmitter, would be the critical mediator of neuromuscular neural activity during developmental synapse elimination (O'Brien et al., 1978). However, glutamate and glutamate receptors also mediate transmission at the NMJ (Waerhaug and Ottersen, 1993; Berger et al., 1995; Grozdanovic and Gossrau, 1998; Mays et al., 2009; Malomouzh et al., 2011; Walder et al., 2013). Glutamate at the NMJ is derived from enzymatic breakdown of $\mathrm{N}$-acetylaspartylglutamate (NAAG), which is released from the motor nerve terminal (Marmiroli et al., 
2012). NAAG is hydrolyzed within the synaptic cleft into glutamate and $N$-acetylaspartate by glutamatecarboxypeptidase II (GCPII), which is expressed extracellularly by terminal Schwann cells (Marmiroli et al., 2012). Glutamate is then available to bind postsynaptic NMDA and AMPA receptors at the end plate. AMPA and NMDA receptors have been documented in rodent myotubes (Lück et al., 2000) and adult muscles (Berger et al., 1995; Grozdanovic and Gossrau, 1998; Mays et al., 2009) and in adult lizard muscles (Walder et al., 2013).

Given the massive evidence that glutamate participates in activity-dependent developmental plasticity via NMDA receptors in the brain (Berardi et al., 2000; Volianskis et al., 2015), we have used three independent methods to investigate whether glutamate, acting on NMDA receptors, contributes to the reduction of polyneuronal innervation at the NMJ. The three methods used to decrease activation of neuromuscular glutamate receptors during the period of synapse elimination were as follows: (1) local application of NMDA and AMPA receptor blockers, (2) reduction of expression of neuromuscular NMDA receptors, and (3) inhibition of the enzyme that produces glutamate from NAAG. All three manipulations significantly slowed synapse elimination. Conversely, we found that withdrawal of excess synaptic innervation was accelerated by local application of exogenous NMDA. In addition, we used calcium imaging to examine the response of the muscles to NMDA and found that there were significant rises in calcium levels at the NMJ during the first 2 postnatal weeks, the postnatal age range when synapse elimination occurs.

\section{Materials and Methods}

Animals

Experiments were performed in postnatal day 4 (P4)-P28 pups or adult CD-1 mice of either sex (Charles River Laboratories). Procedures were approved by the Institutional Animal Care and Use Committee of the University at Buffalo. Animals were euthanized by intraperitoneal injection of ketamine/xylazine $(200 \mathrm{mg} / \mathrm{kg}$ and $20 \mathrm{mg} / \mathrm{kg}$, respectively).

\section{Elvax implants}

For slow release of drugs, Elvax 40W beads (gift from DuPont; method adapted from Cline et al., 1987) were washed in 3-4 changes of $95 \%$ ethanol for 1 week with continuous stirring and then dried on filter paper. Next, $100 \mathrm{mg}$ of beads were dissolved in $900 \mu \mathrm{l}$ of methylene chloride in a glass culture tube. AP5 (100 $\mu \mathrm{M})$ (catalog \#0106; R\&D Systems), CNQX (100 $\mu \mathrm{M}$; catalog \#104510; Fisher Scientific), GCPII $(20 \mu \mathrm{M})$, NMDA (100 $\mu \mathrm{M}$; catalog \#0114; R\&D Systems), or saline was dissolved in $1 \%$ fast green in DMSO and the Elvax mixture was vortexed at medium speed for $3 \mathrm{~min}$ and poured onto a glass slide with a piece of Parafilm cut to form a spacer. The slide was placed on powdered dry ice and a second slide was clamped on top of the first slide. The Elvax was transferred to $-70^{\circ}$ for $2-5 \mathrm{~d}$ and then moved to $-20^{\circ}$. The Elvax was briefly rehydrated with saline before use. To implant the Elvax, P4 pups were anesthetized on ice until a surgical plane of anesthesia occurred when body temperature reached $12-16^{\circ} \mathrm{C}$. A small incision was made in the lateral skin of the distal hindlimb and the fascial plane between the anterior and posterior compartments was cut. A $3 \times 4 \mathrm{~mm}$ rectangle of Elvax was placed bilaterally between the two compartments. The incision was sutured and pups were returned to the litter after warming. Drugimpregnated Elvax was placed in one leg and control Elvax was placed in the opposite leg. The Elvax was left in place until P11 (AP5, CNQX, and CGPII) or P8 (NMDA).

Immunohistochemistry

Muscles were immersion fixed for $15 \mathrm{~min}$ in $4 \%$ paraformaldehyde, rinsed $3 \times$ in PBS, stained with $10 \%$ rhodamine-conjugated $\alpha$-bungarotoxin (catalog \#T1175; Life Technologies), bathed overnight in primary antibodies SV2 (synaptic vesicles, 1:20, RRID:AB_2315390 and 2H3 neurofilament, 1:10, RRID:AB_531793; Developmental Studies Hybridoma Bank) and visualized by secondary antibody Alexa Fluor 488 donkey anti-mouse (RRID:AB_2556542, catalog \#R37114; Life Technologies). Slides were coverslipped with Vectashield mounting medium. To label GCPII and terminal Schwann cells, the primary mouse monoclonal antibody GCP-04 (1:100, gift from Jan Konvalinka, Academy of Science of the Czech Republic) and rabbit polyclonal antibody S100 (1:250, DAKO), respectively, were used. Primary antibodies were visualized by the appropriate Alexa Fluor 488 (1:200) and 568 (1:100) secondary antibodies (Life Technologies).

\section{Analysis of multiple innervation}

Immunostained NMJs were analyzed by conventional epifluorescence microscopy ( $63 \times$ oil objective, BX51; Olympus) or confocal microscopy ( $63 \times$ oil objective, LSM 510 Meta NLO; Zeiss). The number of axons innervating the Ach receptor (AchR) region was counted in 22-212 muscle fibers $(111 \pm 4$, mean \pm SEM) per muscle $(n=7-13)$. The examiner was blinded to experimental or control side. No distinction was made between end plates with innervation by two versus more than two axons.

\section{vivo-morpholinos}

Using the sequence for the mouse GRIN1 gene, Gene Tools constructed a 25 base vivo-morpholino to knock down expression of the GluN1 subunit of the NMDA receptor (Moulton and Jiang, 2009). A total of 10 $\mathrm{nl}$ of a $50 \%$ solution diluted in saline $(400 \mathrm{~nm})$ was pressure injected at 6 sites parallel to the tibialis anterior end plate band along the proximal $1 / 3$ of the muscle of anesthetized $\mathrm{P} 4$ pups. A scrambled-sequence vivomorpholino was injected in the contralateral limb. Innervation of the NMJ was assessed by immunohistochemistry at P11.

\section{Calcium imaging}

Solutions and drugs. A magnesium-free Ringer's medium was used for all experiments. It contained the following (in mM): $25 \mathrm{NaHCO}_{3}, 2$ $\mathrm{CaCl}_{2}, 11$ glucose, 0.4 glutamine, 15 BES [ $N, N$-bis(2-hydroxyethyl)-2aminoethanesulfonic acid], $113 \mathrm{NaCl}, 2 \mathrm{KCl}, 0.01$ glycine, 0.036 choline chloride, $4.34 \times 10^{-}{ }^{7}$ cocarboxylase, bubbled in $95 \% \mathrm{O}_{2} / 5 \% \mathrm{CO}_{2} ; 0.1$ atropine and $0.004 \mu \mathrm{M}$ tubocurarine were included to minimize activation of cholinergic receptors. Muscles were incubated for $30 \mathrm{~min}$ in Ringer's medium with $10 \mu \mathrm{g} / \mathrm{ml}$ rhodamine $\alpha$-bungarotoxin (which served both to enable visualization of the end plate and to block cholinergic receptors), $1 \mu \mathrm{l} / \mathrm{ml}$ Pluronic F-127 (20\% solution in DMSO, catalog \#P-3000MP; Life Technologies; used to disperse the acetoxymethyl esters of Fluo-4), and $10 \mu \mathrm{l} / \mathrm{ml}$ Fluo-4 AM (1 mM solution in DMSO, catalog \#F-14217; Life Technologies) and then rinsed for a minimum of $20 \mathrm{~min}$ in Ringer's medium.

Imaging. Experiments were performed at room temperature (20$24^{\circ} \mathrm{C}$ ). Control images were collected with an Olympus BX51WI microscope equipped for epifluorescence using an FITC filter (excitation wavelength 490, emission 520). An Olympus $40 \times$ (numerical aperture 0.8 ) water-immersion lens was used. Slices were placed in a perfusion chamber (Warner Instruments) with a $230 \mu$ l working bath volume and perfused at a rate of $2 \mathrm{ml} / \mathrm{min}$. Excitation light was provided by a $103 \mathrm{~W} / 2$ mercury short arc lamp (Olympus) and was attenuated by using neutral density filters to avoid photobleaching. Images were collected with a Cooke Sensicam QE. Exposure times were $300 \mathrm{~ms}$ and frames were taken every 3 s. Acquisitions were performed with SLIDEBOOK software (Intelligent Imaging Innovations). For each field of end plates, the following sequence of captures was followed: control, control, AP5 + NMDA, control, NMDA, and control. Intervals after capture sequences were 3 $\min$ for the first 2 control solutions and 5 min subsequently. Any muscles that failed to show responses to NMDA were checked for viability by exposure to $30 \mathrm{~mm} \mathrm{KCl}$; only those that visibly contracted were used for analysis. The attached nerve was not stimulated during these experiments except via depolarization during the final high potassium exposures.

Image analysis was performed in Fiji (ImageJ). For measurement of changes in $\mathrm{Ca}^{2+}$ response, a region of interest over the AchR receptor region was identified (visualized by rhodamine $\alpha$-bungarotoxin). Changes of calcium levels are presented as normalized $\Delta F / F$, where $F$ is the resting fluorescence (before stimulation) and $\Delta F$ is the peak change in fluorescence from resting levels. Fluorescence values were assessed after normalizing by subtracting fluorescence intensity in the region of inter- 
est over the AchRs from adjacent control areas of the same size. More than $74 \%$ of the fibers within the P4-P14 muscles responded to NMDA. The data were collected from the responsive fibers.

\section{Statistics}

Frequency of multiple versus single innervation was assessed by Student's two-tailed $t$ test. Pre-NMDA versus post-NMDA $\mathrm{Ca}^{2+}$ imaging relative brightness was assessed by paired $t$ test. The data variances met the criteria for use of $t$ tests. A one-way ANOVA was used to compare $\mathrm{Ca}^{2+}$ imaging after pre-AP5, post-AP5, and AP5 treatment. Significance was defined as $p<0.05$.

\section{Results}

\section{Glutamate receptor antagonist treatment}

To test whether neuromuscular glutamatergic signaling influences developmental synaptic competition, we applied NMDA and AMPA receptor blockers locally at the NMJ from P4$\mathrm{P} 11$, a part of the period when pruning of connections is under way. The NMDA and AMPA antagonists AP5 [(2R)-amino-5phosphonovaleric acid, $100 \mu \mathrm{M}$ ] and CNQX (6-cyano-7-nitroquinoxaline-2,3-dione, $100 \mu \mathrm{M}$ ) were incorporated into the slow-release polymer Elvax, a $3 \times 4 \mathrm{~mm}$ slice of which was implanted subcutaneously in the hindlimb of P4 CD-1 mouse pups. Drug-free Elvax was inserted into the opposite hindlimb as an internal control. The flexion-withdrawal reflex and walking coordination were assessed 1-3 d after surgery. Pups with impaired motor responses $(<10 \%$ of the total) were not analyzed. After $7 \mathrm{~d}$ of treatment, the muscles were immunolabeled to show end plates and motor axons and the numbers of multiply and singly innervated NMJs were counted (Fig. 1A, left). The ionotropic glutamate receptor antagonists significantly slowed the withdrawal of multiple innervation in both the soleus and extensor digitorum longus (EDL) muscles (Fig. 1A, right). This result suggests that ionotropic glutamate receptors normally promote the reduction of polyneuronal innervation, even in the presence of normal cholinergic transmission.

\section{NMDA receptor knockdown}

To examine the role of glutamate receptors using a different experimental approach and to specifically test the role of NMDA receptors, we used vivo-morpholinos to knock down expression of the obligate GluN1 subunit of the NMDA receptor. AntiGluN1 or random-sequence vivo-morpholinos (Moulton and Jiang, 2009) (400 nM) were injected extracellularly through a glass micropipette attached to a custom-built pressure injector set to 15 pounds per square inch at the end plate band of the tibialis anterior muscles of $\mathrm{P} 4 \mathrm{CD}-1$ pups. Muscles were removed after $7 \mathrm{~d}$, immunolabeled, and the percentage of multiply innervated junctions determined (Fig. $1 B$, left). Again, the fibers on the experimental side demonstrated greater multiple innervation (Fig. $1 B$, right). These results identify the NMDA receptor as a key ionotropic glutamate receptor involved in pruning excess inputs at the developing NMJ.

\section{Inhibition of glutamate production}

Our next experiment addressed the hypothesis (Fig. 2A) that glutamate at the NMJ is derived from NAAG, a peptide neurotransmitter that is highly expressed in motor neurons (Neale and Malomouzh, 2000; Malomouzh et al., 2011). NAAG is hydrolyzed within the synaptic cleft into glutamate and NAA by GCPII, which is expressed extracellularly by terminal Schwann cells (Marmiroli et al., 2012). Using primary antibody GCP-04 (Sácha et al., 2007), we determined that GCPII is expressed at the NMJ during postnatal development, consistent with the observations of Berger et al. (1995). Figure 2B shows that GCPII in the EDL muscle of $\mathrm{P} 11 \mathrm{CD}-1$ pups is expressed in a pattern similar to that of terminal Schwann cells, as indicated by staining with the antibody S-100. If the glutamate that activates NMDA receptors at the NMJ does arise from cleavage of NAAG by GCPII, then inhibition of GCPII activity should reduce available glutamate and diminish NMDA receptor activation, thus slowing the withdrawal of excess innervation. To test this idea, we impregnated Elvax polymer with the GCPII blocker 2-PMPA [2(phosphonomethyl)pentane-1,5-dioic acid, $20 \mu \mathrm{M}$; Thomas et al., 2001] and implanted experimental or saline-impregnated Elvax subcutaneously in the hindlimb of P4 CD-1 pups. At P11, significantly more multiple innervation was seen in the experimental fibers than in contralateral controls (Fig. 2C). These results substantiate our hypothesis that locally derived glutamate activates NMDA receptors at the NMJ and contributes to synapse elimination.

\section{Addition of exogenous NMDA}

If pruning of polyneuronal innervation is slowed or stopped by the reduction of NMDA receptor activity, then we reasoned that the converse might also be true: that the maturation process might be accelerated by enhanced amounts of NMDA itself (Cline and Constantine-Paton, 1990; Udin and Scherer, 1990). We therefore inserted Elvax impregnated with $100 \mu \mathrm{M}$ NMDA or with saline under the skin of the hindlimb in P4 CD-1 pups. Muscles were removed, not at P11 as in the previous experiments, but at $\mathrm{P} 8$, when many junctions normally are still multiply innervated. The muscles were treated for only $4 \mathrm{~d}$ and we were testing whether NMDA would reduce the expected high incidence of multiple innervation. NMDA treatment significantly accelerated synapse elimination in both the EDL and soleus (Fig. 3). Therefore, not only does reducing NMDA-receptor-mediated transmission slow the reduction of polyneuronal innervation of the NMJ, but its converse, chronic activation of NMDA receptors with exogenous NMDA, speeds the reduction of polyneuronal innervation.

\section{Calcium imaging}

We used the calcium indicator Fluo-4 to examine the effect of activating NMDA receptors in the EDL muscle at P4-P28 and in adults. Bath application of NMDA $(200 \mu \mathrm{M})$ evoked significant relative calcium-induced fluorescence in muscles of $\mathrm{P} 4-\mathrm{P} 14$, ages when excess innervation is still being eliminated. NMDA did not increase Fluo-4 brightness in the older juvenile or adult tissue (Fig. $4 A, B$ ). The $\mathrm{Ca}^{2+}$ response to NMDA was largely blocked by the NMDA antagonist AP5 (200 $\mu \mathrm{M})$. Therefore, NMDA has a significant impact on juvenile muscles during the same period when axon pruning occurs, but not on older muscles.

\section{Discussion}

This study provides evidence that glutamate plays a major role in synaptic pruning at the developing mammalian NMJ. The slowing of this process by reduction of NMDA receptor activation was demonstrated by three experimental methods: (1) infusion of NMDA and AMPA receptor blockers at the NMJ, (2) reduction of NMDA receptor expression by blocking transcription of NR1 subunits with antisense vivo-morpholinos, and (3) reducing availability of glutamate by using 2-PMPA to block the enzyme that cleaves NAAG into NAA and glutamate at the NMJ. We also showed that, conversely, pruning could be accelerated by application of exogenous NMDA at the NMJ. We also demonstrated 


\section{A}
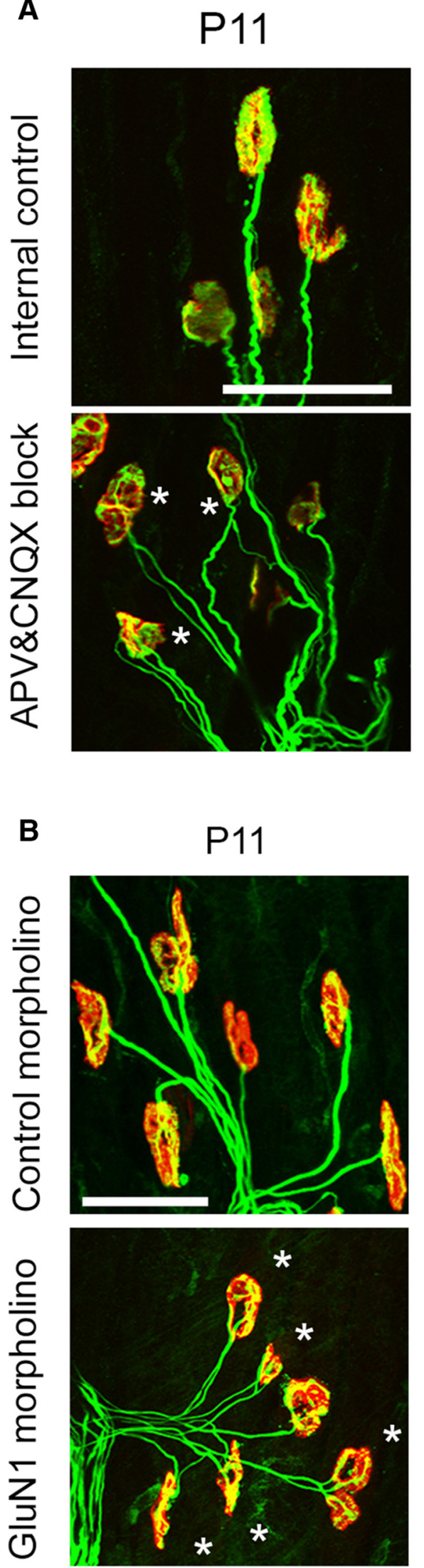

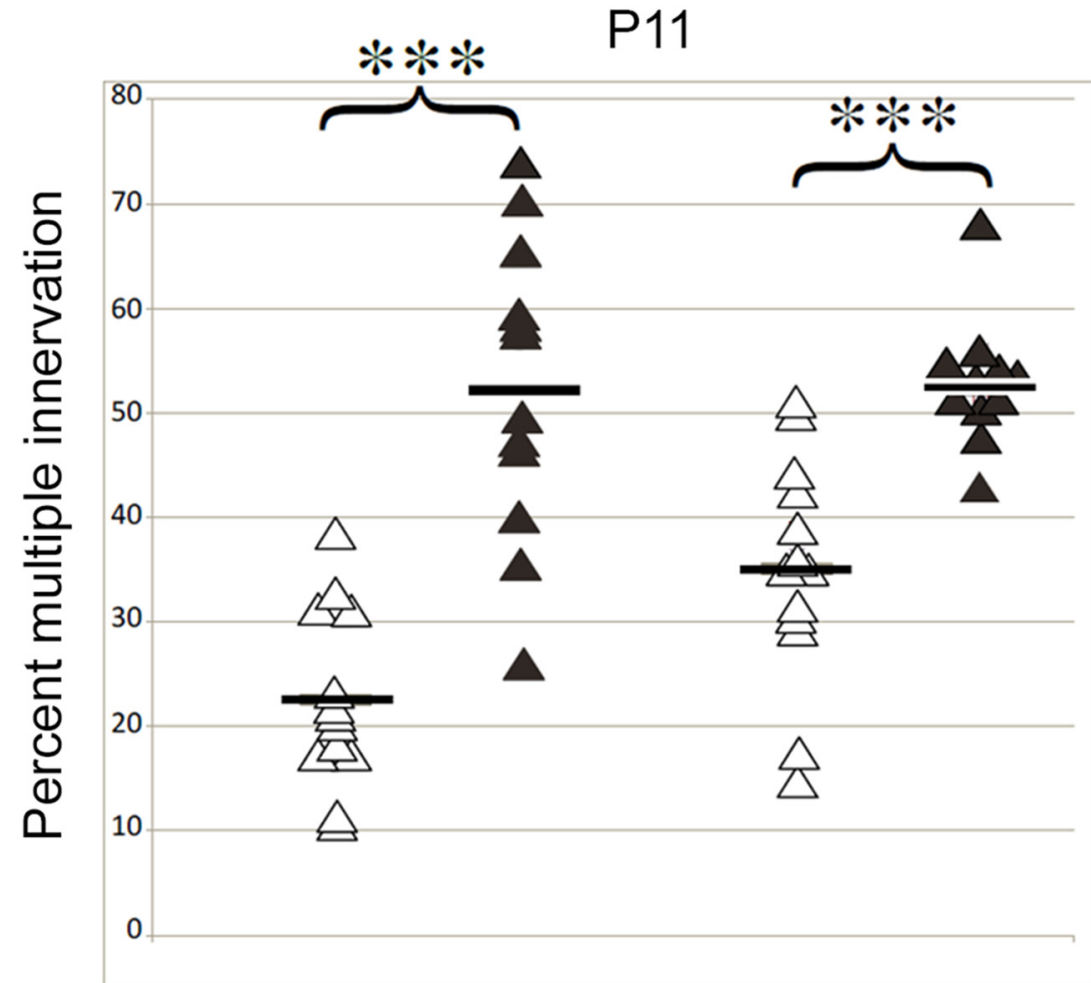

EDL


AT

Figure 1. Reduction of NMDA receptor activity slows synapse elimination. $A$, Pharmacological reduction of NMDA and AMPA receptor activity with AP5 and CNQX between P4 and P11. Left, Whole-mount NMJ immunolabeling in anterior tibialis (AT) muscle of P11 pups. Asterisks show polyinnervated end plates. Red, Rhodamine- $\alpha$-bungarotoxin labels ACh receptors. Green, Antibodies SV2 and 2H3 label synaptic vesicles and neurofilaments. Right, Means and distributions of percentage of multiply innervated muscles. Open symbols indicate control; filled symbols, treated; horizontal lines, means. The treated muscles contained significantly more multiply innervated fibers than the contralateral internal control muscles (Figure legend continues.) 
A

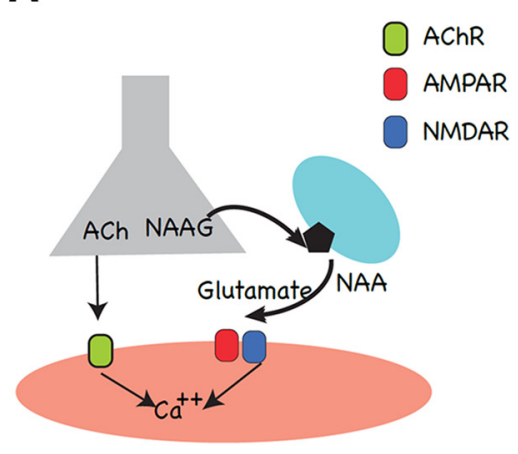

B

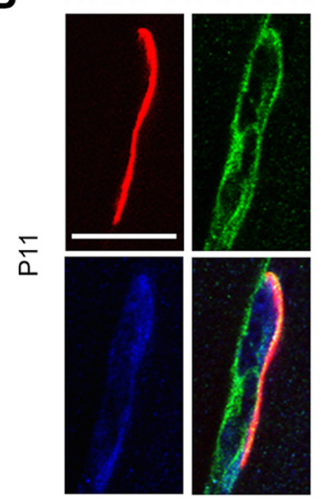

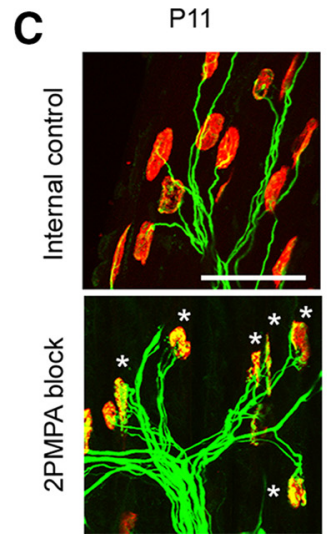

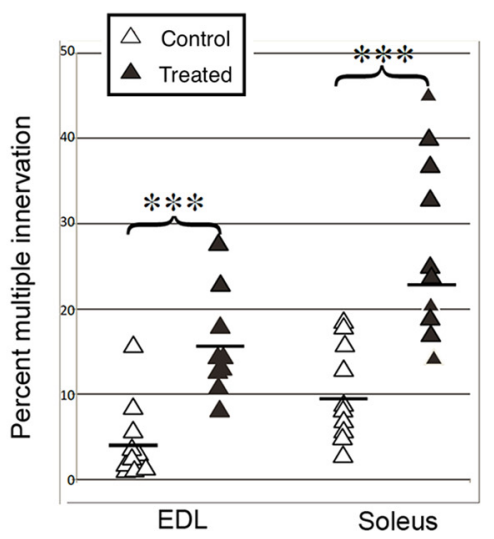

Figure 2. GCPII antagonist slows synapse elimination. A, Model of glutamate production and induction of calcium level influx at the NMJ. The motor neuron terminal (gray) releases ACh and NAAG. GCPII on the Schwann cell (cyan) cleaves NAAG into NAA and glutamate. Glutamate then activates AMPA and NMDA receptors on the muscle (orange), leading to further calcium influx. $\boldsymbol{B}$, Presynaptic expression of the enzyme GCPII during the period of synapse elimination. Whole mount of a P11 EDL muscle immunolabeled for GCPII, AChR, and terminal Schwann cells using the antibody GCP-04 against GCPII (green), rhodamine- $\alpha$-bungarotoxin (red), and S100 against Schwann cells (blue). Scale bar, $25 \mu \mathrm{m}$. C, GCPII antagonist slows synapse elimination by reducing glutamate at the NMJ. Muscles treated with 2-PMPA-infused Elvax contained higher proportions of multiply innervated fibers than internal control muscles (EDL: $4 \pm 1 \%$ control limb vs $15 \pm 2 \%$ treated $\operatorname{limb}, p=0.0004, n=9,10$; soleus: $9 \pm 2 \%$ control limb vs $26 \pm 3 \%$ treated $\operatorname{limb}, p=0.004, n=11,11)$. Scale bar, $50 \mu \mathrm{m}$.
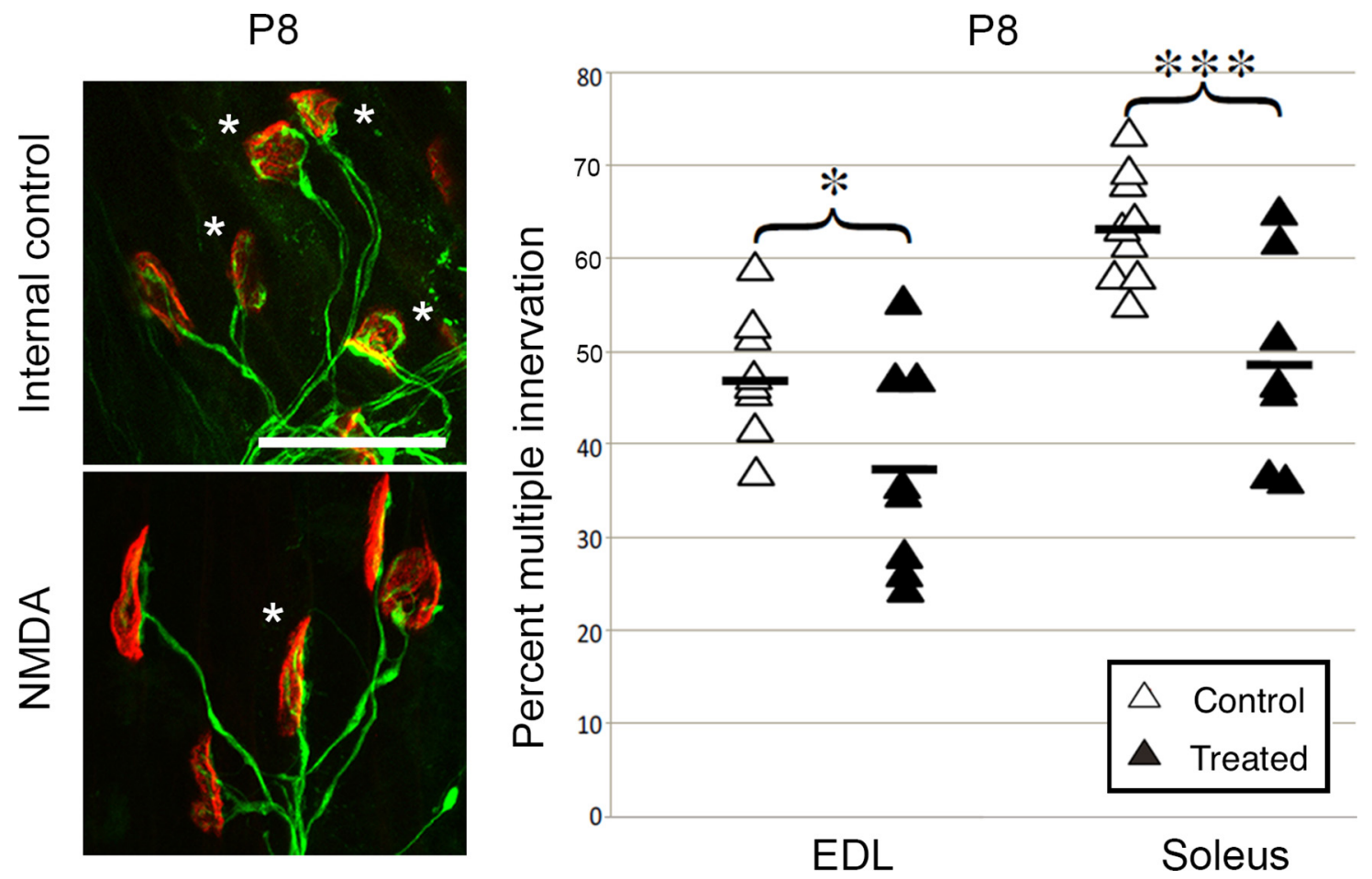

Figure 3. Exogenous NMDA accelerates removal of excess innervation. Left, Examples of multiply innervated (asterisks) and singly innervated end plates in control and NMDA-treated muscles at P8. Scale bar, $50 \mu \mathrm{m}$. Right, NMDA-treated muscles at P8 had significantly fewer multiply innervated fibers than control. Open symbols indicate control; filled symbols, treated (EDL: $48 \pm 2 \%$, control limb vs $38 \pm 4 \%$ vs NMDA-treated limb, $p=0.05, n=8$, 9; soleus: $63 \pm 2 \%$, control limb vs $49 \pm 4 \%$, NMDA-treated limb, $p=0.014, n=7,8$ ).

that the response of the muscles to NMDA changed during postnatal development, with rises in calcium levels only during the first 2 postnatal weeks, a period that coincides with the transition from polyneuronal to single innervation of the muscles.

\section{$\leftarrow$}

(Figure legend continued.) (EDL: $22 \pm 3 \%$ control limb vs $52 \pm 4 \%$ treated limb, $p=$ $0.00006, n=12,12$; soleus: $35 \pm 3 \%$ control limb vs $53 \pm 2 \%$ treated limb, $p=0.00001, n=$ 11, 13). B Vivo-morpholino downregulation of GluN1 expression between P4 and P11. A vivomorpholino was pressure injected into the AT muscle end plate band in P4 pups. Conventions are as in $\boldsymbol{A}$. The AT muscle demonstrated significant retention $(9 \pm 5 \%$ internal control limb vs $24 \pm 8 \%$ treated limb, $p=0.001, n=8,8)$. Scale bars, $50 \mu \mathrm{m}$.
It should be stressed that AchRs were not blocked in any of our in vivo experiments. One might have thought that any contribution from the NMDA receptors would be swamped by the preponderance of cholinergic transmission. However, the configuration of the early postnatal NMJ is quite unlike that of the adult. For example, at P3, the about half of the AChR plaque is occupied by terminal Schwann cells, whereas the nerve terminals are confined to only about $1 / 4$ of the plaque (Smith et al., 2013). This arrangement limits access of ACh to postsynaptic AChRs. Moreover, the large access of Schwann cell processes to the synaptic cleft may be especially favorable for enzymatic production of glutamate from NAAG, with consequent activation of gluta- 
mate receptors. The glutamate produced by GCPII on the terminal Schwann cell membranes is likely to have the greatest access to the end plate during the first 2 postnatal weeks. Therefore, there may be a relatively high ratio of glutamatergic-tocholinergic activation of the muscle during early postnatal development, with a significant drop later when the synaptic structure matures and the nerve occupies the majority of the plaque. This early preponderance of glutamatergic influence may explain why singly innervated terminals are found on muscles fibers that are genetically modified to prevent ACh release (Buffelli et al., 2003).

There is a striking correlation between the period of axon pruning and when muscles show significant calcium responses to bath-applied NMDA. This correlation further bolsters the hypothesis that NMDA receptors play a role in the maturation of neuromuscular innervation. How do they do so? Does NMDA receptor activation stabilize favored synapses or does it destabilize the synapses that withdraw? Ultimately, only one axon will be stabilized, whereas the remainder will be destabilized and withdrawn. This phenomenon has prompted hypotheses based on dual mechanisms, with differential patterns of activity leading the muscle to release a positive signal that stabilizes one input while it simultaneously creates a negative signal that destabilizes the other inputs (Je et al., 2013). Our results imply that NMDA receptor activation may amplify any activity imbalance among the competing inputs; the strongest inputs would lead to the largest positive and negative feedback signals, but the negative signals would have larger net impact on the weaker connections. Therefore, exogenous NMDA accelerates axon elimination, as in Figure 3, whereas reduction of NMDA receptor activation slows axon elimination (Figs. 1,2). Together, these results imply that NMDA receptor activation triggers events that ultimately destabilize all but the strongest inputs at the NMJ.

During the second postnatal week, there is overlap between the influence of NMDA receptors on axon elimination and the influence of the MHC1 members of the major histocompatibility complex at the NMJ (Tetruashvily et al., 2016). The MHC1 molecules, like NMDA receptors, seem to play a role in synapse elimination. Unlike NMDA receptors, however, their expression is minimal until week 2 and rises thereafter (Tetruashvily et al., 2016). We have not tested whether the effect of reducing NMDA receptor activation leads to permanent polyinnervation, so it is possible that NMDA receptor effects predominate in the early postnatal weeks, with other factors such as AChRs and MHC1 molecules leading to completion of the process.

Our results are consistent with the hypothesis that NAAG is a major source of glutamate at the immature NMJ. Immunolabeling shows colocalization of GCPII with markers for Schwann cells and reducing GCPII activity slows the elimination of supernumerary inputs to the NMJ during development. The possibility also remains that glutamate itself is released by motor nerve terminals after transport from the cell body (Kerkut et al., 1967) or after reuse of the glutamate produced from NAAG (Rinholm et al., 2007). However, a study of rat motor neurons found that neither VGLUT1 nor VGLUT2 is expressed at the NMJ (Herzog et al., 2004).

\section{Conclusions}

These observations support the hypothesis that activation of neuromuscular NMDA receptors is highly important during the postnatal period, when polyneuronal innervation is subject to reduction through activity-mediated mechanisms. It should be stressed that the in vivo experiments were performed in the absence of any inhibitors of AchR activity. Therefore, the early weeks of postnatal development represent a period in which NMDA receptors play a hitherto unappreciated role in synapse elimination, in some respects even dominating that of AchRs.

\section{References}

Berardi N, Pizzorusso T, Maffei L (2000) Critical periods during sensory development. Curr Opin Neurobiol 10:138-145. CrossRef Medline

Berger UV, Carter RE, Coyle JT (1995) The immunocytochemical localization of $\mathrm{N}$-acetylaspartyl glutamate, its hydrolysing enzyme NAALADase, and the NMDAR-1 receptor at a vertebrate neuromuscular junction. Neuroscience 64:847-850. CrossRef Medline

Buffelli M, Burgess RW, Feng G, Lobe CG, Lichtman JW, Sanes JR (2003) Genetic evidence that relative synaptic efficacy biases the outcome of synaptic competition. Nature 424:430-434. CrossRef Medline

Cline HT, Constantine-Paton M (1990) NMDA receptor agonist and antagonists alter retinal ganglion cell arbor structure in the developing frog retinotectal projection. J Neurosci 10:1197-1216. Medline

Cline HT, Debski EA, Constantine-Paton M (1987) N-methyl-D-aspartate receptor antagonist desegregates eye-specific stripes. Proc Natl Acad Sci U S A 84:4342-4345. CrossRef Medline

Favero M, Busetto G, Cangiano A (2012) Spike timing plays a key role in 
synapse elimination at the neuromuscular junction. Proc Natl Acad Sci U S A 109:E1667-1675. CrossRef Medline

Grozdanovic Z, Gossrau R (1998) Co-localization of nitric oxide synthase I (NOS I) and NMDA receptor subunit 1 (NMDAR-1) at the neuromuscular junction in rat and mouse skeletal muscle. Cell Tissue Res 291: 57-63. Medline

Herzog E, Gilchrist J, Gras C, Muzerelle A, Ravassard P, Giros B, Gaspar P, El Mestikawy S (2004) Localization of VGLUT3, the vesicular glutamate transporter type 3, in the rat brain. Neuroscience 123:983-1002. CrossRef Medline

Je HS, Yang F, Ji Y, Potluri S, Fu XQ, Luo ZG, Nagappan G, Chan JP, Hempstead B, Son YJ, Lu B (2013) ProBDNF and mature BDNF as punishment and reward signals for synapse elimination at mouse neuromuscular junctions. J Neurosci 33:9957-9962. CrossRef Medline

Kerkut GA, Shapira A, Walker RJ (1967) The transport of 14C-labelled material from CNS to and from muscle along a nerve trunk. Comp Biochem Physiol 23:729-748. CrossRef Medline

Lück G, Hoch W, Hopf C, Blottner D (2000) Nitric oxide synthase (NOS-1) coclustered with agrin-induced AChR-specializations on cultured skeletal myotubes. Mol Cell Neurosci 16:269-281. CrossRef Medline

Malomouzh AI, Nurullin LF, Arkhipova SS, Nikolsky EE (2011) NMDA receptors at the end plate of rat skeletal muscles: precise postsynaptic localization. Muscle Nerve 44:987-989. CrossRef Medline

Marmiroli P, Slusher B, Cavaletti G (2012) Tissue distribution of glutamate carboxypeptidase II (GCPII) with a focus on the central and peripheral nervous system. Curr Med Chem 19:1277-1281. CrossRef Medline

Mays TA, Sanford JL, Hanada T, Chishti AH, Rafael-Fortney JA (2009) Glutamate receptors localize postsynaptically at neuromuscular junctions in mice. Muscle Nerve 39:343-349. CrossRef Medline

Moulton JD, Jiang S (2009) Gene knockdowns in adult animals: PPMOs and vivo-morpholinos. Molecules 14:1304-1323. CrossRef Medline

Neale JH, Bzdega T, Wroblewska B (2000) N-Acetylaspartylglutamate: the most abundant peptide neurotransmitter in the mammalian central nervous system. J Neurochem 75:443-452. Medline

O’Brien RA, Ostberg AJ, Vrbová G (1978) Observations on the elimination of polyneuronal innervation in developing mammalian skeletal muscle. J Physiol 282:571-582. CrossRef Medline

Personius KE, Balice-Gordon RJ (2001) Loss of correlated motor neuron activity during synaptic competition at developing neuromuscular synapses. Neuron 31:395-408. CrossRef Medline

Personius KE, Chang Q, Mentis GZ, O'Donovan MJ, Balice-Gordon RJ
(2007) Reduced gap junctional coupling leads to uncorrelated motor neuron firing and precocious neuromuscular synapse elimination. Proc Natl Acad Sci U S A 104:11808-11813. CrossRef Medline

Redfern PA (1970) Neuromuscular transmission in new-born rats. J Physiol 209:701-709. CrossRef Medline

Rinholm JE, Slettalokken G, Marcaggi P, Skare Ø, Storm-Mathisen J, Bergersen LH (2007) Subcellular localization of the glutamate transporters GLAST and GLT at the neuromuscular junction in rodents. Neuroscience 145:579-591. CrossRef Medline

Sácha P, Zámecník J, Barinka C, Hlouchová K, Vícha A, Mlcochová P, Hilgert I, Eckschlager T, Konvalinka J (2007) Expression of glutamate carboxypeptidase II in human brain. Neuroscience 144:1361-1372. CrossRef Medline

Sanes JR, Lichtman JW (2001) Induction, assembly, maturation and maintenance of a postsynaptic apparatus. Nat Rev Neurosci 2:791-805. Medline

Smith IW, Mikesh M, Lee YI, Thompson WJ (2013) Terminal Schwann cells participate in the competition underlying neuromuscular synapse elimination J Neurosci 33:17724-17736. CrossRef

Tetruashvily MM, McDonald MA, Frietze KK, Boulanger LM (2016) MHCI promotes developmental synapse elimination and aging-related synapse loss at the vertebrate neuromuscular junction. Brain Behav Immun 56: 197-208. CrossRef Medline

Thomas AG, Liu W, Olkowski JL, Tang Z, Lin Q, Lu XC, Slusher BS (2001) Neuroprotection mediated by glutamate carboxypeptidase II (NAALADase) inhibition requires TGF-beta. Eur J Pharmacol 430:33-40. CrossRef Medline

Thompson W (1983) Synapse elimination in neonatal rat muscle is sensitive to pattern of muscle use. Nature 302:614-616. CrossRef Medline

Udin SB, Scherer WJ (1990) Restoration of the plasticity of binocular maps by NMDA after the critical period in Xenopus. Science 249:669-672. CrossRef Medline

Volianskis A, France G, Jensen MS, Bortolotto ZA, Jane DE, Collingridge GL (2015) Long-term potentiation and the role of N-methyl-D-aspartate receptors. Brain Res 1621:5-16. CrossRef Medline

Waerhaug O, Ottersen OP (1993) Demonstration of glutamate-like immunoreactivity at rat neuromuscular junctions by quantitative electron microscopic immunocytochemistry. Anat Embryol 188:501-513. Medline

Walder KK, Ryan SB, Bzdega T, Olszewski RT, Neale JH, Lindgren CA (2013) Immunohistological and electrophysiological evidence that $\mathrm{N}$-acetylaspartylglutamate is a cotransmitter at the vertebrate neuromuscular junction. Eur J Neurosci 37:118-129. CrossRef Medline 